\title{
Exploratory study of tolerability and immunological effect of a short up-dosing immunotherapy phase with a standardised allergen extract derived from pollen of Olea europaea
}

\author{
Carmen Moreno ${ }^{1}$, Blanca Sáenz De San Pedro², Carmen Millán ${ }^{3}$, Carmen Panizo ${ }^{4}$, Santiago Martín ${ }^{5^{*}}$
} and Fernando Florido ${ }^{6}$

\begin{abstract}
Background: A new subcutaneous specific immunotherapy (SCIT) product adsorbed on aluminium hydroxide has been developed with a short and simplified up-dosing phase, containing a biologically standardized allergen pollen extract from Olea europaea.

Objective: To assess the tolerability profile of the updosing phase and its immunological effect, in terms of specific $\operatorname{lgG}_{4}$ and $\lg E$ levels and immediate skin reactivity.

Material and methods: The study was an exploratory, multi-centre, open-label, single-arm, phase II/III clinical trial. Adults with a clinical history of allergic rhinoconjunctivitis with/without asthma due to sensitization to olive pollen were selected. Five up-dosing doses (300,600, 3000, 6000 and 15000SQ+) were administered at weekly intervals, followed by a maintenance dose (15000SQ+) after 2 weeks. Adverse events were collected during the 30 min observation period after injections, after a telephone contact 2 days after each visit, and after reviewing the subjects' diary. $\operatorname{lgG}_{4}$ and IgE levels and immediate skin reactivity were evaluated at the beginning and at the end of the trial.
\end{abstract}

Results: Ninety-three subjects were included in the trial (mean age, $35.7 \pm 10.3$ years; women, $66.7 \%$ ). A total of 95 adverse drug reactions, all mild in intensity and non-serious, were reported during the trial: 85 local in $34.4 \%$ subjects, 9 systemic in $4.3 \%$ subjects and one non-specific (grade 0). Within 6 weeks, significant changes in $\operatorname{lgG}_{4}$ and lgE levels and in immediate skin reactivity to Olea europaea were accomplished.

Conclusion: This new SCIT derived from pollen of Olea europaea presented a good tolerability profile and induced significant immunological responses already after a 6 week treatment. However, the non-controlled design may limit the interpretation of these results.

Trial registration: EudraCT no: $2011-004852-20$; ClinicalTrials.gov Identifier: NCT01674595.

Keywords: Allergen-specific immunotherapy, Allergen, Olive pollen allergy, Immune response, Skin reactivity, Tolerability, Seasonal allergic rhinitis

\footnotetext{
* Correspondence: santiago.martin@alk.net

${ }^{5}$ Medical Department, ALK-Abelló S.A., C/ Miguel Fleta, 19, Madrid 28037, Spain

Full list of author information is available at the end of the article
} 


\section{Background}

Allergic rhinoconjunctivitis and asthma are, frequently, concurrent disorders $[1,2]$, which has led to the notion that these two conditions are different aspects of the same disease $[3,4]$. Results from the ONEAIR study, a prospective observational study conducted between 2004 and 2005 with 942 subjects from Spain, reinforced this idea, highlighting that almost $90 \%$ of subjects suffering from asthma presented concomitant allergic rhinitis [5].

The ability of olive pollen (Olea europaea) to induce notorious symptoms of rhinitis and/or asthma in exposed populations through an IgE-mediated mechanism is amply documented in the Mediterranean areas [6-12]. A study conducted in 4000 allergic subjects from all over Spain showed that $47 \%$ of subjects suffering from allergic rhinoconjunctivitis and $51 \%$ of asthmatics were sensitized to Olea europaea, which emphasizes the importance of olive pollen allergen in Spain [13].

Available treatment options in respiratory allergic conditions include allergen avoidance, symptomatic treatment and etiologic treatment. Olive pollen allergen avoidance is hardly applicable since only a limited reduction in exposure can be achieved by modifying life habits. Symptomatic treatment offers short-term symptomatic relief, but does not offer long-term benefit, as the natural course of the disease is not affected. Etiologic treatment with allergenspecific immunotherapy (AIT) has proven to be the most effective treatment option for allergic diseases. AIT involves administering specific allergens to patients suffering from IgE-mediated allergic diseases in order to ameliorate symptoms, induce sustained and long-term immunological tolerance to the causative allergen, and potentially alter the natural course of the disease [14-16].

The subcutaneous route for the administration of AIT products has been proven to be clinically efficacious and well-tolerated in a number of studies [17-19]. The standard schedule for the subcutaneous immunotherapy (SCIT) starts with an induction period or up-dosing phase, involving increasing weekly doses over a number of consecutive weeks (12-14 weeks) until the maintenance dose is reached; however, there has been growing interest in reducing the initiation period to facilitate AIT compliance [20]. A new SCIT product containing allergen extract of Olea europaea (AVANZ ${ }^{\circ}$ Olive) has been developed based on previous SCIT products.

Therefore, all the above considerations prompted us to assess the tolerability and the immunological effect of the up-dosing phase of this new SCIT containing allergen extract derived from olive pollen.

\section{Methods}

\section{Study design}

This was an open-label, single-arm, phase II/III multicenter clinical trial conducted at 10 sites in Spain, where olive pollen is an important cause of rhinitis and/or bronchial asthma. The study was approved by the applicable ethics committees and by the Spanish Drug Agency, and written informed consent was obtained from all subjects before their inclusion in the study. The trial was conducted in accordance with the Declaration of Helsinki [21] and in compliance with the Good Clinical Practice Guidelines [22]. The trial was registered on ClinicalTrials.gov under identification number NCT01674595.

\section{Study population}

The study population comprised adult subjects aged 18 to 65 years with a clinical history of olive pollen-induced allergic rhinoconjunctivitis and/or asthma at least 1 year prior to trial entry, a positive skin prick test (SPT) response to Olea europaea (wheal diameter $\geq 3 \mathrm{~mm}$ ), and a positive specific IgE against olive pollen ( $\geq$ IgE class 2 ; $\geq$ $0.70 \mathrm{KU} / \mathrm{L})$ documented within the last 5 years. Subjects with forced expiratory volume in $1 \mathrm{~s}$ (FEV1) $<70 \%$ of the predicted value at screening, uncontrolled or severe asthma, and a history of severe asthma exacerbation [23] were not included in the study. Subjects were also excluded if they had had an emergency room visit/admission because of asthma within the previous 12 months, a history of anaphylactic shock due to food, insect venom, exercise or drug, or severe and recurrent angioedema, or previous treatment with olive AIT within the previous 5 years or other concomitant AIT.

\section{Interventions}

The trial was initiated after the olive pollen season of 2012. AVANZ $^{\circ}$ Olive injections were given by trained nurses and under supervision of expert allergists in Immunotherapy Units following national and international recommendations [24].

Subjects were administered 5 weekly subcutaneous up-dosing injections (300 SQ+, $600 \mathrm{SQ}+, 3000 \mathrm{SQ}+$, $6000 \mathrm{SQ}+$ and 15,000 SQ+), followed by the maintenance injection (15,000 SQ) 2 weeks after, as part of the short course of SCIT (6 weeks). Two days after each visit, subjects were contacted by telephone to record any adverse event.

\section{Evaluations}

Tolerability (primary endpoint) was assessed throughout the study as the incidence of adverse drug reactions (ADR) recorded during the $30 \mathrm{~min}$ waiting period after each injection, through phone calls 2 days after each injection and by reviewing the patients' diaries issued to record any untoward experience. ADRs were defined as all noxious and unintended responses to any dose of the Investigational Medicinal Product (IMP) administered, and were classified as immediate (within $30 \mathrm{~min}$ after the injection) or delayed ( $>30 \mathrm{~min}$ after the injection). 
Likewise, ADRs were classified as local (LR, reactions occurring at the injection site), or systemic (SR, generalised signs/symptoms occurring away from the injection site). All LRs were recorded, regardless of size, including (diffuse) swelling, redness (erythema), pain, itching (pruritus) or injection site reaction (if two or more local symptoms occurred simultaneously); SRs were graded by the investigator according to the European Academy of Allergy and Clinical Immunology (EAACI) guidelines [24]. Additionally, all AEs where coded according to the Medical Dictionary for regulatory Activities (MedDRA).

At SCIT initiation (visit 1) and 6 weeks after the beginning of SCIT (visit 6), SPT to 5-fold concentrations of Olea europaea allergen extracts $(12,60$ and $300 \mu \mathrm{g} / \mathrm{ml}$ Ole e 1) was performed and blood samples were taken for immunological assessments (secondary endpoint), including Olea europaea-specific $\operatorname{IgG}_{4}$ and IgE levels by ImmunoCAP (Phadia AB Uppsala). Changes in immediate skin response to Olea europaea were analyzed using the parallel line assay (PLA) [25], expressed as the cutaneous tolerance index (CTI), which indicates the difference in allergen concentration needed to elicit the same response.

\section{Statistical considerations}

Statistical analyses were performed on the full analysis set of subjects, using the available data without imputation of missing values. The tolerability profile was determined using descriptive analyses. Changes in specific $\operatorname{IgG}_{4}$ and $\operatorname{IgE}$ levels between visit 1 and visit 6 were performed using Student's $t$-test for paired samples. All statistical analyses were performed using the Statistical Package for the Social Sciences (SPSS) version 17.

\section{Results}

From September 2012 to April 2013, a total of 96 subjects were enrolled in the trial; as three subjects failed screening, 93 subjects were administered the IMP. Of these, three subjects discontinued before completing the study treatment (Fig. 1). The subjects' baseline characteristics are presented in Table 1.

\section{Tolerability}

Thirty-four subjects (36.6 \%) of IMP-exposed participants reported a total of 95 ADRs during the trial (Table 2). All ADRs were mild in intensity and nonserious, and all participants recovered fully. In one subject dose adjustment due to ADRs was done. A total of 85 local ADRs were reported by 32 (34.4\%) subjects without leading to changes in the administration schedule. Nine systemic ADRs were reported in 4 (4.3\%) subjects, all mild, non-serious, delayed and EAACI grade I.

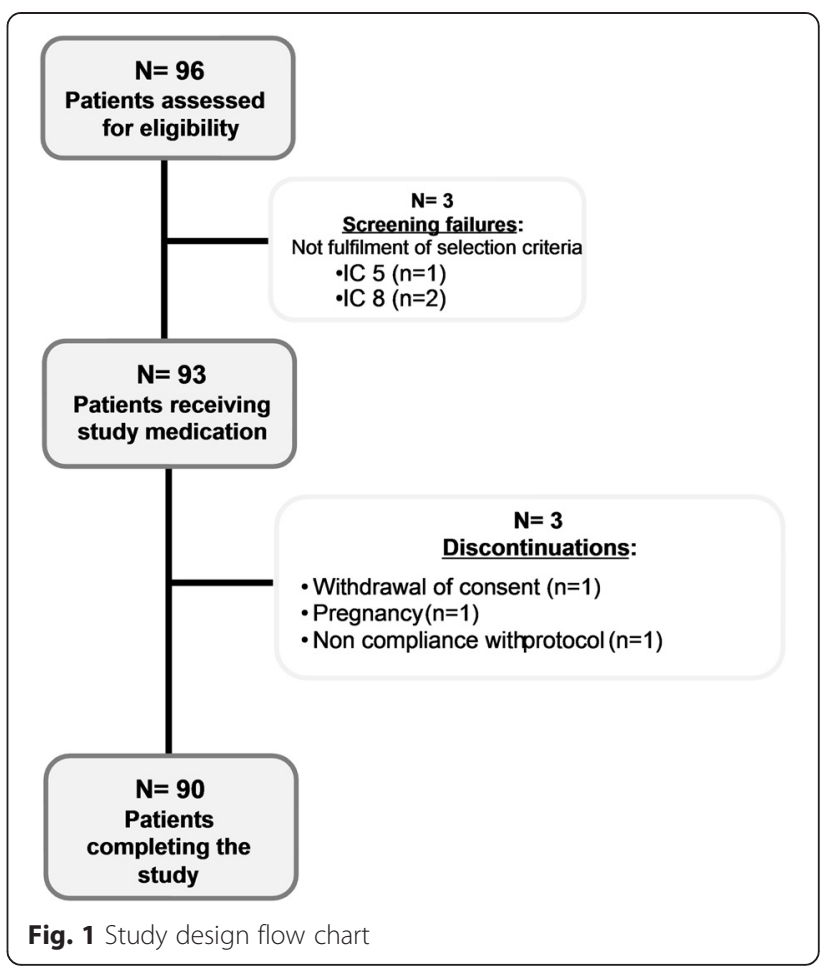

One subject experienced 4 SRs with different doses, two subjects two SRs each with the same dose and one subject only one SR. All dose concentrations elicited SRs and no risks were associated with a particular dose. SRs consisted in asthma symptoms and oticus and pharyngeal pruritus. Table 3 shows the nature of local and SRs by MedDRA System Organ Class (SOC) and Preferred Term (PT). One subject reported a nonspecific (grade 0) ADR. No subjects required treatment with adrenaline and no safety concerns were raised for vital signs. IMP-unrelated AEs accounted for 84 events in 34 subjects.

\section{Immunological effect}

A statistically significant increase of $\mathrm{IgG}_{4}$ and $\mathrm{IgE}$ levels to Olea europaea was observed from visit 1 to visit 6 (Table 4). Furthermore, within 6 weeks of treatment with Olea europaea SCIT, a significant reduction in immediate skin reactivity was observed with a CTI of 2.34 (95\% confidence interval (CI), 1.72 - 3.19). Changes in immediate skin reactivity over time are shown in Fig. 2.

\section{Discussion}

Olive pollen is one of the most important causes of inhalant allergy in the Mediterranean countries [26] and is becoming the main disease-eliciting pollen in some provinces of Southern Spain (i.e. Córdoba, Jaén). The aim of this study was to determine the tolerability profile of the up-dosing phase of the new SCIT with Olea europaea allergen extract, measured as the incidence of 
Table 1 Subjects' baseline characteristics $(N=93)$

\begin{tabular}{|c|c|}
\hline Baseline characteristics & Value \\
\hline Age (years), mean $\pm S D$ & $35.7 \pm 10.3$ \\
\hline Women, n (\%) & $62(66.7)$ \\
\hline \multicolumn{2}{|l|}{ Ethnic origin, $n(\%)$ : } \\
\hline Caucasian & $89(95.7)$ \\
\hline Hispanic & $3(3.2)$ \\
\hline Arabian & $1(1.1)$ \\
\hline \multicolumn{2}{|l|}{ Main concomitant illness, n (\%): } \\
\hline Asthma & $64(68.8)$ \\
\hline Rhinoconjunctivitis & $93(100)$ \\
\hline $\mathrm{BMI}\left(\mathrm{kg} / \mathrm{m}^{2}\right)$, mean $\pm \mathrm{SD}$ & $25.9 \pm 4.2$ \\
\hline \multicolumn{2}{|l|}{ Vital signs, mean $\pm S D$ : } \\
\hline Systolic blood pressure (mmHg) & $120.2 \pm 13.7$ \\
\hline Diastolic blood pressure (mmHg) & $73.7 \pm 8.8$ \\
\hline Heart rate (bpm) & $74.2 \pm 8.1$ \\
\hline \multicolumn{2}{|l|}{ Smoking habits, n (\%): } \\
\hline Non-smoker & $72(77.4)$ \\
\hline Smoker & $14(15.1)$ \\
\hline Previous smoker & $7(7.5)$ \\
\hline \multicolumn{2}{|l|}{ IgE Olea europaea CAP class, n (\%): } \\
\hline 2 & $16(17.2)$ \\
\hline 3 & $32(34.4)$ \\
\hline 4 & $28(30.1)$ \\
\hline 5 & $12(12.9)$ \\
\hline 6 & $5(5.4)$ \\
\hline
\end{tabular}

BMI body mass index, bpm beats per minute, $n$ (\%) number and percentage of subjects, $S D$ standard deviation

ADRs. The trial was designed as non-controlled and as so, subjected to a certain degree of bias which may limit the interpretation of the results. However, regarding tolerability, the frequency of ADRs can be considered conservative, because all AEs with a temporary relation to the treatment with no other attributable cause have been related to the studied treatment. With regards to the immunological endpoints, the specificity of the immunological evaluations does not require a control group as it would be the case of a clinically-related endpoint.

The nature of the ADRs observed during treatment with this new SCIT was as expected. Over one-third of the study population suffered at least one ADR. All ADRs were mild in intensity, occurred at all dosing steps, most were related to the injection site and all participants achieved full recovery. Only one subject interrupted temporally the dosing schedule.

We have followed the current guidelines of the European Medicines Agency (EMA) on clinical development of AIT [27] and all AEs have been coded with MedDRA.
Table 2 Summary of adverse drug reactions

\begin{tabular}{|c|c|c|}
\hline & e & n (\%) \\
\hline IMP-related adverse events & 95 & $34(36.6)$ \\
\hline \multicolumn{3}{|l|}{ Severity } \\
\hline Mild & 95 & $34(36.6)$ \\
\hline Moderate & 0 & 0 \\
\hline Severe & 0 & 0 \\
\hline \multicolumn{3}{|l|}{ Change in treatment schedule } \\
\hline None & 93 & $33(35.5)$ \\
\hline Temporarily interrupted & 2 & $1(1.1)$ \\
\hline Discontinued & 0 & 0 \\
\hline Prior to first intake & 0 & 0 \\
\hline \multicolumn{3}{|c|}{ Classification according to EAACl guideline } \\
\hline$L R$ & 85 & $32(34.4)$ \\
\hline SR & 9 & $4(4.3)$ \\
\hline Grade 0/Nonspecific & 1 & $1(1.1)$ \\
\hline \multicolumn{3}{|l|}{ Dose } \\
\hline $300 \mathrm{SQ}+$ & 16 & $13(14.0)$ \\
\hline $600 \mathrm{SQ}+$ & 11 & $11(11.8)$ \\
\hline $3,000 \mathrm{SQ}+$ & 24 & $22(23.7)$ \\
\hline $6,000 \mathrm{SQ}+$ & 17 & $17(18.3)$ \\
\hline $15,000 \mathrm{SQ}+$ & 26 & $15(16.1)$ \\
\hline Dose unknown & 1 & $1(1.1)$ \\
\hline
\end{tabular}

$A D R$ adverse drug reaction, e number of events, EAACI European Academy of Allergy and Clinical Immunology, $n(\%)$ number and percentage of subjects, $L R$ local reactions, $S Q+$ standardized quality units, $S R$ systemic reactions

Consequently, all local ADRs have been reported, independently of their size. These two factors, together with the way AEs were registered, proactively with a phone call 2 days after each injection and with a subject diary, may explain the apparently higher rate of ADRs in this

Table 3 Nature of adverse drugs reactions

\begin{tabular}{lll}
\hline System organ class and preferred term & $\mathrm{e}$ & $\mathrm{n}(\%)$ \\
\hline Ear and labyrinth disorders & 1 & $1(1.1)$ \\
Ear pruritus & & \\
General disorders and administration site conditions & 1 & $1(1.1)$ \\
Asthenia* & 1 & $1(1.1)$ \\
Chest discomfort & 1 & $1(1.1)$ \\
Injection site erythema & 3 & $3(3.2)$ \\
Injection site pain & 25 & $12(12.9)$ \\
Injection site pruritus & 52 & $22(23.7)$ \\
Injection site reaction & 4 & $3(3.2)$ \\
Injection site swelling & & \\
Respiratory, thoracic and mediastinal disorders & 4 & $1(1.1)$ \\
Asthma & 3 & $3(3.2)$ \\
Throat irritation &
\end{tabular}

$e$, number of events; $n$ (\%), number and percentage of subjects

* EAACl Grade 0 (No symptoms or nonspecific symptoms of systemic reaction) 
Table 4 Levels of $\operatorname{lgG}_{4}$ and $\lg E$ to Olea europaea

\begin{tabular}{llllll}
\hline & $\mathrm{n}$ & Visit 1 (mean $\pm \mathrm{SD})$ & Visit 6 (mean $\pm \mathrm{SD})$ & Effect size & $p$-value* \\
\hline $\operatorname{lgG}_{4}\left(\mathrm{mg}_{\mathrm{A}} / \mathrm{l}\right)$ & 90 & $0.34 \pm 0.37$ & $0.97 \pm 1.13$ & 0.64 & $<0.001$ \\
$\lg \mathrm{K}(\mathrm{KU} / \mathrm{l})$ & 90 & $34.07 \pm 36.09$ & $47.50 \pm 47.82$ & 13.43 & $<0.001$ \\
\hline
\end{tabular}

$n$ number of subjects with valid data in visit 1 and visit $6, S D$ standard deviation

*p-values correspond to paired Student's $t$-test

trial. Although it is difficult to compare the safety profile between trials due to these differences in the safety reporting methodology, the pattern of the ADRs observed in this trial seems to be in line with previous experience and with what has been observed in previous clinical trials with other AIT products [28, 29].

A similar clinical trial led by Tabar AI [30], conducted with 102 subjects with the same SCIT formulation containing a house dust mite (Dermatophagoides mix)-derived allergen extract, showed similar results in terms of number and nature of the ADRs, with $4.9 \%$ of the study population reporting mild, grade I SRs and a similar rate of LRs. In a randomised open controlled study of SCIT with a similar Olea europaea standardised allergen extract quantified in mass units performed with a conventional up-dosing schedule in a province of the Southern region of Spain (Jaén), where pollen counts may reach 7000 grains $/ \mathrm{m}^{3}$, Gonzalez et al. [28] reported similar results with a rate of SRs of $8.7 \%$, with 3 mild and 1 moderate reactions.

One of the secondary endpoints of our study was to determine the immunological effect of this new SCIT formulation by measuring the specific levels of IgE and $\mathrm{IgG}_{4}$. Specific immunoglobulin levels are essential to establish the immune response of allergen immunotherapy, as the induction of $\operatorname{IgG}_{4}$ potentially blocks the proportion of IgE-facilitated antigen to T cells and eosinophils, resulting in a reduction of IgE production and the inflammatory response [29]. As might be expected, this new SCIT with olive pollen allergen extract induced immunological responses reflected as statistically

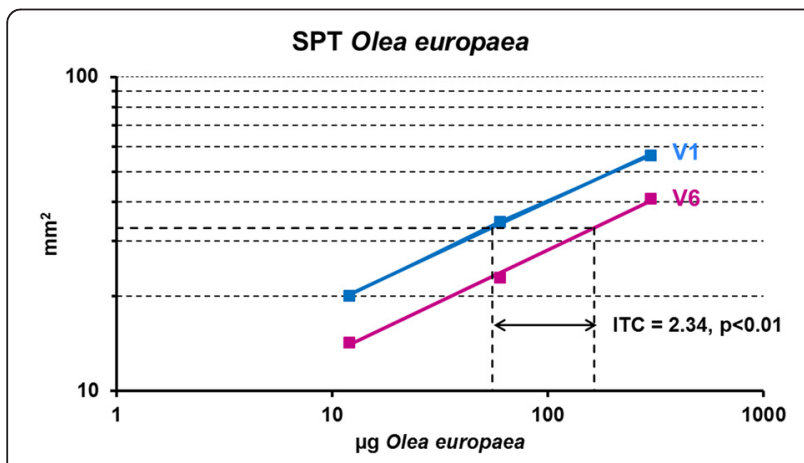

Fig. 2 Changes in immediate skin reactivity by parallel line assay. Subjects were prick-tested with an Olea europaea pollen allergen extract containing 12,60 and $300 \mu \mathrm{g} / \mathrm{ml}$ Ole e 1 before (V1) and after (V6) 6 week treatment. The reduction of skin reactivity was assessed by parallel line assay. CTI, Cutaneous Tolerance Index significant increments of specific levels of $\operatorname{IgE}$ and $\operatorname{Ig} G_{4}$ within 6 weeks of therapy. AIT often induces a shortterm increase in IgE levels followed by a long-term decrease and a rapid increase in $\operatorname{IgG}_{4},[19,28,31,32]$ which can block the binding of IgE to allergens and B cells. The induction of T-regulatory cells (Treg) by AIT is central to the suppression of the allergic reaction: Treg produce IL-10 which is able to suppress IgE production by $B$ cells and to induce $\operatorname{IgG}_{4}$ [33].

Several studies have evaluated the effect of SCIT on cutaneous reactivity to the causative allergen, showing continuous reduction in cutaneous response, which in some studies has been seen to correlate with clinical efficacy [34]. In our study, we achieved progressive reduction in immediate skin reactivity to the different concentrations of olive allergen extract, expressed as the CTI, i.e. the factor by which the extract concentration has to be multiplied to obtain the same response as in the beginning in a linear dose-response relationship. Recently, Tabar AI et al. [30] reported similar results, achieving a CTI of 1.44 (95\% CI, 1.04 - 1.98) after 6 weeks of immunotherapy. Likewise, clinical trials led by Martínez-Cocera [35] and Vidal [36] showed similar reductions in skin reactivity after a short course of AIT with allergen extract derived from Phleum pratense and house dust mites, respectively.

\section{Conclusion}

The results of this phase II/III clinical trial show that immunotherapy with a biologically standardized allergen extract derived from Olea europaea in a 6 week schedule has a good tolerability profile and induces significant immunological responses in subjects suffering from allergic rhinoconjunctivitis and/or asthma due to sensitization to olive pollen.

\footnotetext{
Abbreviations

ADR: Adverse drug reaction; AIT: Allergen-Specific Immunotherapy; Cl: Confidence interval; CTI: Cutaneous tolerance index; EAACI: European Academy of Allergy and Clinical Immunology; EMA: European Medicines Agency; FEV1: Forced expiratory volume in 1 second; IMP: Investigational medicinal product; LR: Local reaction; MedDRA: Medical dictionary for regulatory activities; PLA: Parallel line assay; PT: Preferred term; SCIT: Subcutaneous immunotherapy; SOC: System organ class; SPSS: Statistical package for the social sciences; SPT: Skin prick test; SR: Systemic reaction; Treg: T-regulatory cells.
}

\section{Competing interests}

Carmen Moreno, Blanca Sáenz De San Pedro, Carmen Millán, Carmen Panizo and Fernando Florido have received grant from ALK-Abelló for the participation in this trial. Santiago Martín is employee of ALK-Abelló. 


\section{Authors' contributions}

SM designed the trial. CMo acted as coordinating investigator and reviewed the trial design, protocol and assessments. All authors analysed the results and discussed the conclusions and actively participated in the elaboration of the manuscript. All authors have read and approved the final manuscript.

\section{Acknowledgements}

The following principal investigators also participated in the trial: J. Borja ( $\mathrm{H}$. General Universitario de Ciudad Real), L. Alonso González (H. La Mancha Centro, Ciudad Real), J. González Cervera (H. Tomelloso, Ciudad Real), A. Vega $(H$. Universitario de Guadalajara) and P. Guardia $(H$. Universitario Virgen Macarena, Sevilla).

\section{Author details}

${ }^{1}$ Hospital Universitario Reina Sofía, Córdoba, Spain. ${ }^{2}$ Complejo Hospitalario de Jaén, Jaén, Spain. ${ }^{3}$ Hospital de Jerez de la Frontera, Cádiz, Spain. ${ }^{4}$ Servicio de Salud de Castilla La Mancha, Hospital Nuestra Señora del Prado, Talavera de la Reina, Toledo, Spain. ${ }^{5}$ Medical Department, ALK-Abelló S.A., C/ Miguel Fleta, 19, Madrid 28037, Spain. ${ }^{6}$ Hospital Universitario San Cecilio, Granada, Spain.

\section{Received: 13 April 2015 Accepted: 16 June 2015}

\section{Published online: 24 July 2015}

\section{References}

1. Asher MI, Montefort S, Bjorksten B, Lai CK, Strachan DP, Weiland SK, et al. Worldwide time trends in the prevalence of symptoms of asthma, allergic rhinoconjunctivitis, and eczema in childhood: ISAAC phases One and three repeat multicountry cross-sectional surveys. Lancet. 2006;368(9537):733-43.

2. Jarvis D, Newson R, Lotvall J, Hastan D, Tomassen P, Keil T, et al. Asthma in adults and its association with chronic rhinosinusitis: the GA2LEN survey in Europe. Allergy. 2012;67(1):91-8.

3. Bousquet J, Vignola AM, Demoly P. Links between rhinitis and asthma. Allergy. 2003;58(8):691-706.

4. Morjaria JB, Caruso M, Rosalia E, Russo C, Polosa R. Preventing progression of allergic rhinitis to asthma. Curr Allergy Asthma Rep. 2014;14(2):412.

5. Navarro A, Valero A, Julia B, Quirce S. Coexistence of asthma and allergic rhinitis in adult patients attending allergy clinics: ONEAIR study. J Investig Allergol Clin Immunol. 2008;18(4):233-8.

6. Quiralte J, Florido F, de Saavedra JM A, Gomez A, Saenz de San Pedro B, Gonzalez E, et al. Olive allergen-specific IgE responses in patients with Olea europaea pollinosis. Allergy. 2002;57 Suppl 71:47-52.

7. D'Amato G, Lobefalo G. Allergenic pollens in the southern Mediterranean area. J Allergy Clin Immunol. 1989;83(1):116-22.

8. Liccardi G, D'Amato M, D'Amato G. Oleaceae pollinosis: a review. Int Arch Allergy Immunol. 1996;111(3):210-7.

9. Subiza Garrido-Lestache J. [Allergenic pollens in Spain]. Allergol Immunopathol (Madr). 2004:32(3):121-4.

10. Celenk S, Canitez Y, Bicakci A, Sapan N, Malyer H. An aerobiological study on pollen grains in the atmosphere of North-West Turkey. Environ Monit Assess. 2009:158(1-4):365-80.

11. Gonzalez Minero FJ, Candau P. Olea europaea airborne pollen in southern Spain. Ann Allergy Asthma Immunol. 1997;78(3):278-84.

12. Subiza J, Jerez M, Jimenez JA, Narganes MJ, Cabrera M, Varela S, et al. Allergenic pollen pollinosis in Madrid. J Allergy Clin Immunol. 1995;96(1):15-23.

13. Sociedad Española de Alergia e Inmunología Clínica, ALK-Abelló, S.A. Alergológica. Factores Epidemiológicos, Clínicos y Socioeconómicos de las Enfermedades Alérgicas en España. Madrid; 1995

14. Bousquet J, Lockey R, Malling HJ. Allergen immunotherapy: therapeutic vaccines for allergic diseases. A WHO position paper. J Allergy Clin Immunol. 1998;102(4 Pt 1):558-62.

15. Purkey MT, Smith TL, Ferguson BJ, Luong A, Reisacher WR, Pillsbury III HC, et al. Subcutaneous immunotherapy for allergic rhinitis: an evidence based review of the recent literature with recommendations. Int Forum Allergy Rhinol. 2013;3(7):519-31.

16. Greiner AN, Hellings PW, Rotiroti G, Scadding GK. Allergic rhinitis. Lancet. 2011;378(9809):2112-22.

17. Olaguibel JM, Tabar Al, Garcia BE, Martin S, Rico P. Long-term immunotherapy with an optimal maintenance dose of a standardized Dermatophagoides pteronyssinus extract in asthmatic patients. J Investig Allergol Clin Immunol. 1999;9(2):110-6.
18. Powell RJ, Frew AJ, Corrigan CJ, Durham SR. Effect of grass pollen immunotherapy with Alutard SQ on quality of life in seasonal allergic rhinoconjunctivitis. Allergy. 2007;62(11):1335-8

19. Tabar Al, Arroabarren E, Echechipia S, Garcia BE, Martin S, Alvarez-Puebla MJ. Three years of specific immunotherapy may be sufficient in house dust mite respiratory allergy. J Allergy Clin Immunol. 2011;127(1):57-63. 1.

20. Parmiani S, Fernandez TL, Moreno C, Guardia P, Rico P. Clustered schedules in allergen-specific immunotherapy. Allergol Immunopathol (Madr). 2002;30(5):283-91

21. World Medical Association. The Declaration of Helsinki: Ethical Principles for Medical Research Involving Human Subjects.First adopted in 1964 (Helsinki, Finland) and revised in 1975 (Tokyo, Japan), 1983 (Venice, Italy), 1989 (Hong Kong), 1996 (Somerset-West, South Africa) and 2000 (Edinburgh, Scotland). Note of clarification, 2002 (Washington). 1996 Oct. Available from: http:// www.fda.gov/ohrms/dockets/dockets/06d0331/06D-0331-EC20-Attach-1.pdf.

22. ICH Harmonised Tripartite Guideline E6 S5. Guideline for Good Clinical Practice. 1996

23. Reddel HK, Taylor DR, Bateman ED, Boulet LP, Boushey HA, Busse WW, et al. An official american thoracic society/european respiratory society statement: asthma control and exacerbations: standardizing endpoints for clinical asthma trials and clinical practice. Am J Respir Crit Care Med. 2009;180(1):59-99.

24. Alvarez-Cuesta E, Bousquet J, Canonica GW, Durham SR, Malling HJ, Valovirta E. Standards for practical allergen-specific immunotherapy. Allergy. 2006;61 Suppl 82:1-20.

25. Martin S, Cuesta P, Rico P, Cortes C. A computer program based on parallel line assay for analysis of skin tests. Allergy. 1997;52(1):97-100.

26. Bousquet J, Guerin B, Hewitt B, Lim S, Michel FB. Allergy in the Mediterranean area. III: cross reactivity among oleaceae pollens. Clin Allergy. 1985;15(5):439-48.

27. Committee for medicinal products for human use (chmp). guideline on the clinical development of products for specific immunotherapy for the treatment of allergic diseases.http://www.ema.europa.eu/docs/en_GB/ document_library/Scientific_guideline/2009/09/WC500003605.pdf.

28. Gonzalez P, Florido F, Saenz de San Pedro B, de la Torre F, Rico P, Martin S. Immunotherapy with an extract of Olea europaea quantified in mass units. Evaluation of the safety and efficacy after 1 year of treatment. J Investig Allergol Clin Immunol. 2002;12(4):263-71.

29. Wachholz PA, Durham SR. Mechanisms of immunotherapy: IgG revisited. Curr Opin Allergy Clin Immunol. 2004;4(4):313-8.

30. Tabar Al, González Delgado P, Sánchez Hernández C, Basagaña Torrento M Moreno Benítez F, Arina M. Phase II/III clinical trial to assess the tolerability and immunological effect of a new updosing phase of Dermatophagoides mix-based immunotherapy. J Investig Allergol Clin Immunol. 2015;25(1):40-6.

31. Guerra F, Moreno C, Daza JC, Garcia M, Arenas A, Miguel R, et al. IgG4 levels in relation to Olea europaea immunotherapy. J Investig Allergol Clin Immunol. 1992;2(6):307-12.

32. Macchia L, Caiaffa MF, Di FG, Pini C, Bariletto G, Strada S, et al. Changes in skin reactivity, specific lgE and lgG levels after 1 year of immunotherapy in olive pollinosis. Allergy. 1991;46(6):410-8

33. Akdis CA, Akdis M. Mechanisms of immune tolerance to allergens: role of IL-10 and Tregs. J Clin Invest. 2014;124(11):4678-80.

34. Cox L. Accelerated immunotherapy schedules: review of efficacy and safety. Ann Allergy Asthma Immunol. 2006:97(2):126-37.

35. Martinez-Cocera C, Sastre J, Cimarra M, Quirce S, Fernandez-Rivas M, Enriquez-Matas A, et al. Immunotherapy with a Phleum pratense allergen extract induces an immune response to a grass-mix allergen extract. J Investig Allergol Clin Immunol. 2010;20(1):13-9.

36. Vidal C, Tabar Al, Fiqueroa J, Navarro JA, Sanchez C, Orovitg A, et al. Assessment of short-term changes induced by a Dermatophagoides pteronyssinus extract on asthmatic patients. Randomised, double-blind, placebo-controlled trial. Curr Drug Deliv. 2011;8(2):152-8. 